\title{
Temática apocalíptica medieval en lengua francesa
}

\author{
Salvador RUBIO-REAL \\ Universidad de Huelva \\ salvador.rubio@dfint.uhu.es \\ https://orcid.org/0002-7159-3128
}

Resumen

La literatura apocalíptica en lengua francesa durante el periodo medieval no ha recibido la atención que consideramos necesaria al haber sido eclipsada por la producción literaria en francés, por una parte, y la producción apocalíptica en latín, por otra. Con este artículo pretendemos establecer las bases para un estudio de la temática apocalíptica en lengua francesa con la creación de un corpus de manuscritos franceses de la Edad Media conservados en la Bibliothèque Nationale de France.

Palabras clave: Corpus. Fin del mundo. Literatura en lengua romance. Manuscritos. Bibliothèque Nationale de France.

\section{Résumé}

La littérature apocalyptique en langue française de la période médiévale n'a pas reçu l'attention requise, dû à l'énorme production littéraire en français, d'une part, et dû à la production apocalyptique en langue latine, d'autre part. Avec cet article, nous essayons d'établir les fondations pour une étude de la thématique apocalyptique en langue française avec un corpus de manuscrits français du Moyen Âge, conservés dans les fonds de la Bibliothèque Nationale de France.

Mots-clés : Corpus. Fin du monde. Littérature en roman. Manuscrits. Bibliothèque Nationale de France.

\begin{abstract}
Apocalyptic literature in French during the Medieval period has not received the attention we consider necessary. The enormous literary production in French and the Latin apocalyptic texts has eclipsed almost all the apocalyptic production in Roman languages. With this paper, we establish the foundations of a corpus of French manuscripts from the Middle Ages kept at the Bibliothèque Nationale de France, to understand the apocalyptic thematic in French during this period.
\end{abstract}

\footnotetext{
*Artículo recibido el 16/06/2020, aceptado el 21/01/2021.
} 
Keywords: Corpus. End of the world. Roman literature. Manuscripts. Bibliothèque Nationale de France.

\section{Introducción}

El fin del mundo es un tema ampliamente tratado, no solo en la literatura religiosa de cualquier época, sino también en el ámbito literario. En este sentido, la literatura apocalíptica, tal y como la conocemos, ha evolucionado enormemente desde sus orígenes en la literatura religiosa judía, sufriendo cambios y adaptaciones desde entonces.

El concepto de finitud de la vida humana, que es fundamental para entender la literatura apocalíptica, se extiende a la sociedad entera (Eliade, 2000: 71-73) y, en el caso de las religiones con vocación de universalidad, como el cristianismo y, en menor medida, el islam y el judaísmo, al mundo entero. Esta es la principal característica de la que se alimenta el pensamiento escatológico judeocristiano y, por extensión, la literatura que surge de esta forma de pensar.

La temática apocalíptica medieval ha sido objeto de numerosos estudios, muchos autores se han interesado por las fuentes del pensamiento apocalíptico (Cohn, 2001) o por su evolución dentro de la historia del pensamiento y la literatura (McGinn, 1994), por no citar más que dos ejemplos. Sin embargo, McGinn se ha interesado especialmente en los documentos conservados en lengua latina por ser los documentos conservados más numerosos, mientras que el estudio de Cohn se ha circunscrito al ámbito geográfico de la Europa del Norte. De modo que el número de estudios sobre textos apocalípticos en lengua romance son sensiblemente más escasos. Que no haya grandes estudios sobre la temática apocalíptica en lengua romance me llevó a investigar, en el ámbito de la preparación de mi tesis doctoral, dicha temática. De modo que durante mis estudios de doctorado analicé los principales fondos documentales en Francia y en España con el objeto de establecer un corpus de manuscritos de temática apocalíptica en lengua romance, tanto en español como en francés, redactados a lo largo de los últimos tres siglos de la Edad Media (Rubio, 2016).

Con este artículo, que supone una síntesis de parte de mi investigación doctoral, proponemos una organización de los temas apocalípticos más habituales en la literatura en lengua francesa. Hemos establecido cinco temas que a su vez se reúnen en dos grupos, en función de sus características comunes.

El primer grupo es el que contiene el mayor número de documentos, que por ello hemos denominado temática principal, y engloba tres temas, a saber, el Anticristo, los Signos del Juicio Final y el Juicio Final. Aunque estos tres temas tienen su origen en los evangelios cristianos, se desarrollarán plenamente en la literatura apocalíptica cristiana de la Antigüedad tardía y la Alta Edad Media. 
El segundo grupo, que hemos denominado temática secundaria, comprende dos temas, a saber, el Último Emperador y los Pueblos Inmundos. Estos temas no aparecen de forma aislada en la literatura, sino que forman siempre un episodio dentro de un texto mayor. Aunque están incluidos en la tradición apocalíptica cristiana, su origen es, al contrario que los textos de la temática principal, netamente medieval.

Gnisci (2001: 161) considera que «la tematología se coloca en un cruce estratégico de dinámicas y relaciones con el imaginario, con la historia de las ideas, de las ideologías, de la mentalidad, de la sensibilidad». En un cruce similar hemos establecido este artículo, pues los autores de los documentos que forman nuestro corpus escogieron una serie de temas surgidos de la tradición apocalíptica en lengua latina y crean una nueva tradición, esta vez en lengua romance.

Naupert (2001: 122) considera, en esta misma línea, que «un conjunto "temático" se convierte en objeto de estudio cuando es eco o resonancia reconocible y significativa, cuando acusa creativamente una tradición cultural compartida». En este mismo sentido avanzado por Naupert, consideramos que los manuscritos que constituyen nuestro corpus comparten las características principales que los sitúan dentro de la tradición apocalíptica medieval y, de forma más general, de la tradición apocalíptica judeocristiana.

Con este artículo nos hemos propuesto dos objetivos: en primer lugar, establecer un contexto a la temática apocalíptica medieval en lengua romance; y, en segundo lugar, establecer una serie de criterios temáticos para crear un corpus de textos literarios medievales cuya temática sea el fin del mundo.

\section{Contexto y evolución de la literatura apocalíptica}

El pensamiento apocalíptico, así como la producción literaria que genera, forma un continuum que se mantiene desde sus orígenes judíos hasta la Edad Media. La tradición apocalíptica evoluciona a través de los siglos y de los textos conservados, incluyendo los primeros relatos proféticos judíos de la Biblia hasta las creaciones netamente medievales como el poema Des quinze signes du Jugement Dernier, pasando por los Apocalipsis de los primeros cristianos. De este modo se establece un fructífero diálogo entre el pensamiento apocalíptico y la producción literaria que de dicho pensamiento se deriva, superando incluso los límites de la literatura religiosa.

No obstante, delimitaremos la producción apocalíptica en el tiempo en función de ciertas características. McGinn (1998: 2-36) divide la literatura apocalíptica en varios periodos: en primer lugar, la literatura apocalíptica judía, que se ocupa del apocalipticismo judío desde sus orígenes, allá por el siglo VII a.C. hasta el siglo II a.C. La literatura de este periodo es netamente judía y constituye la base del apocalipticismo cristiano posterior.

En segundo lugar, tenemos el periodo que McGinn (1998) denomina «clásico» y que va del siglo II a.C. hasta, aproximadamente, el siglo II d.C. En este periodo, la 
influencia de la cultura helena, especialmente en el Levante mediterráneo, es notoria. Se observa una confluencia de la tradición judía, las nuevas influencias griegas y la irrupción del cristianismo y su pensamiento apocalíptico.

En tercer lugar, encontramos el periodo patrístico, que se extiende del siglo II al siglo V. Este es el periodo de formación de una literatura apocalíptica netamente cristiana que mantiene y desarrolla las amplias influencias judías y griegas que precedieron a este periodo.

McGinn (1998) señala que la Edad Media constituye el cuarto y último periodo de la evolución del pensamiento apocalíptico, que va del siglo $\mathrm{V}$ al XV. Dado que nuestro artículo se centra en la producción apocalíptica en lengua francesa, haremos una subdivisión entre Alta Edad Media (siglos V-XI) y Baja Edad Media (siglos XII-XV). El grueso de la literatura apocalíptica en lengua romance se circunscribe a este último periodo, de modo que resulta relevante ver dónde la tradición en lengua latina, predominante desde la época patrística, pasa a la lengua romance.

De modo que haremos un breve recorrido por la literatura apocalíptica desde sus orígenes, con el objetivo de determinar qué temas apocalípticos se mantienen en la literatura en lengua romance con respecto a la literatura apocalíptica principal en hebreo, latín y griego.

La literatura apocalíptica judía surge unos 60 años antes del exilio de Babilonia (587 a.C.), aunque, en este sentido, se trata más de literatura profética que apocalíptica (Puech, 1993: 144-146). Sin embargo, la intensidad de sus imágenes y sus motivos han propiciado que se incluya en la tradición apocalíptica occidental. Los textos más conocidos del periodo previo al exilio son los libros de Nehemías, Jeremías e Isaías, que aparecen en el Antiguo Testamento, y el Apocalipsis de Zefanías. Una de las características más notables de dicha literatura, por cuanto tiene de duradera dentro de la tradición apocalíptica, es la de la destrucción del mundo a causa de los pecados humanos. Consideraban que la decadencia y la corrupción de la humanidad en este periodo alcanzaron tal nivel que el fin del mundo debía ser inminente.

Una de las características fundamentales de la literatura apocalíptica de este periodo es la interpretación teológica de la historia, que busca un explicación a la desaparición del estado de Israel tras la invasión y el exilio de Babilonia (Albertz, 1999: 472-475). Esta búsqueda de sentido escatológico será una constante en la literatura apocalíptica posterior.

Además de esta interpretación teológica, se establecen una serie de temas apocalípticos que tendrán un amplio recorrido en la literatura posterior, a saber, los cataclismos cósmicos como signos de la intervención divina, las experiencias visionarias, las acciones simbólicas y el lenguaje sofisticado y lleno de fuerza, que aparecen sobre todo en el libro de Ezequiel. Este libro será una de las mayores y más duraderas influencias de la literatura apocalíptica cristiana como quedará de manifiesto a lo largo de este artículo. 
El siguiente periodo de la literatura apocalíptica judía, siguiendo la división establecida por McGinn, comienza con el regreso del exilio (583 a. C.) y se extiende hasta la conquista de Palestina por parte de Alejandro Magno (333 a. C.). A medida que la influencia helena aumenta, la literatura apocalíptica judía evoluciona hacia posturas más generales, donde se incluye ya a los gentiles. De este periodo, y similares al libro de Ezequiel citado anteriormente, son los libros de Joel y Daniel, que también forman parte del continuum apocalíptico judío y cuyas imágenes y narraciones también tendrán una gran influencia en los apocalipsis cristianos de la Antigüedad tardía.

En este periodo clásico del apocalípticismo occidental se redactan la mayor parte de los Apocalípsis propiamente cristianos, muy influidos, no obstante, por el apocalipticismo judío y las corrientes helenas del periodo anterior. Ambas tendencias provocarán tensiones en el seno de la comunidad judía y, por extensión, en la producción literaria apocalíptica, creando dos tendencias antagónicas dentro de la misma, aquellos que consideran aceptable la influencia helena y aquellos que la consideran perniciosa para las tradiciones judeocristianas.

En esta atmósfera de conflicto entre tradición y modernidad, entre poder político y poder religioso, se redactan la mayoría de los textos apocalípticos que más adelante se conocerán bajo el nombre genérico de apocrypha y pseudoepigrapha, que conformarán el grueso de la producción apocalíptica posterior. La Ley tradicional judía es el marco privilegiado de este tipo de textos que, al ser alimentados por las profecías antiguas, redescubren y aumentan los antiguos anuncios escatológicos (Puech, 1993: 184).

En este periodo de influencias cruzadas, de inestabilidad y de tensiones surgen tanto las primeras iglesias cristianas como sus primeros textos apocalípticos. Es muy difícil, por lo tanto, establecer fronteras claras entre textos judíos y textos cristianos, ya que estos consideraban los textos judíos como propios. Sin embargo, la separación entre cristianos y judíos se hizo rápidamente, debido tanto a la concepción que los primeros cristianos tenían de sí mismos y de su teología como al rechazo que provocaban entre los judíos (Puech, 1993: 243-250).

Cristo y su mensaje sintetizan la esperanza escatológica de la religiosidad judía contemporánea de los primeros cristianos: la aparición del Mesías que liberará al pueblo judío. No olvidemos que los primeros cristianos eran en origen judíos de Jerusalén y formaban una secta apocalíptica inscrita en el judaísmo palestino, al mismo nivel que los esenios de Qumram, entre otros. Teniendo en cuenta que consideraban a Jesús como Mesías, la esperanza escatológica de los primeros cristianos basculó hacia la segunda venida de Jesús, tal y como él la había anunciado, segunda llegada que traía aparejada el fin de la historia. No obstante, su posterior expansión entre los gentiles les obliga a adaptar el discurso (Eliade, 2005: 406-ss). Esta adaptación se extiende a toda la literatura religiosa, incluyendo la literatura apocalíptica. 
Este cambio en la esperanza escatológica de los primeros cristianos opera asimismo un cambio en la literatura apocalíptica, que se centra, a partir de ahora, en la importancia dada a la visión del futuro, mientras que hasta el momento se centraba en la concepción del pasado y su posible relación con los acontecimientos futuros. De manera que la literatura apocalíptica de la época patrística (100-500 d.C.) se ocupa principalmente del futuro, donde impera el análisis sobre aquello que sucederá después de la muerte, ya sea personal o colectiva (Collins, 1996). La historia está predeterminada por la voluntad divina (McGinn, 1998: 15), por lo que el pasado deja de tener interés para los cristianos.

La literatura apocalíptica de este periodo, pues, tiene como objetivo analizar el destino colectivo de la cristiandad. En este periodo se establecen los temas principales de la literatura apocalíptica cristiana que se mantendrán, con algunos cambios, a lo largo de la Antigüedad tardía y la Edad Media: el Anticristo, la duración del mundo y el reino de los mil años.

Siguiendo con la división de McGinn (1998) que señalamos al principio, en este periodo patrístico surgen los oráculos, de origen grecorromano, y los apocalipsis, de origen judío, como principales medios de difusión de la tradición apocalíptica cristiana. Tanto unos como otros tendrán un gran éxito durante toda la Edad Media. A pesar de que el canon bíblico establecido por Ireneo de Lyon en el siglo III solo reconoce un Apocalipsis -el de Juan-, circulaba un gran número de ellos entre los círculos cristianos de dicho periodo, lo que da cuenta del interés que suscitaba el pensamiento apocalíptico en la época. Una de las imágenes más habituales en este tipo de textos es la destrucción final del mundo a través de cataclismos generalizados que preceden el Juicio Final.

Ireneo de Lyon marca, al mismo tiempo, un nuevo punto de inflexión en lo que a literatura apocalíptica se refiere: a pesar del gran número de oráculos y apocalipsis que se redactaron en esta época, el final del periodo conocerá la reorganización del canon y el aumento de la labor de exégesis de la producción apocalíptica cristiana, que será constante a partir de este momento. Salvo excepciones, los temas apocalípticos que dominarán la Edad Media ya se habían establecido en este momento.

La producción apocalíptica medieval (500-1500 d.C.) es, pues, una mezcla de comentarios a los textos canónicos, de reescritura de los mitos apocalípticos precedentes $y$, en menor medida, de inclusión de algunas novedades en la tradición apocalíptica cristiana. La Edad Media, aún más que la Antigüedad, alimentó sus miedos escatológicos a través de los eventos históricos y sociales. Las guerras, los cismas, las invasiones bárbaras, la aparición del islam, las crisis y las epidemias exaltaron ciertos aspectos de la escatología medieval.

Destacan tres textos en este periodo, cuya influencia, como veremos más adelante en el corpus en lengua francesa, es notable: el Apocalipsis de Pseudo-Metodio, del 
siglo VII, el Tratado del Anticristo de Adso de Montier-en-Der, del siglo X, y la producción apocalíptica de Joachim de Fiore durante el siglo XII.

Si bien la literatura apocalíptica de la Edad Media se redacta en latín, durante la Baja Edad Media se produce un bilingüismo de facto entre el latín, mayoritario, y las lenguas romances, en plena expansión. El francés, en el caso que nos ocupa, traduce, adapta e incluso crea nuevos documentos basados en la tradición apocalíptica latina.

Con respecto a la temática, hay ciertos temas que no pasarán a la lengua vulgar o, hasta donde sabemos, no se ha encontrado testimonio documental de dicho paso. No podemos olvidar a este respecto que la sociedad medieval era una sociedad eminentemente oral y los documentos escritos son, por ello, raros y costosos. No obstante, los documentos conservados son una parte significativa de la literatura medieval, pues dan cuenta de los temas y motivos que pasaron de la tradición latina a la incipiente tradición romance.

\section{Establecimiento del corpus}

Hemos establecido tres criterios principales a la hora de escoger los manuscritos franceses de temática apocalíptica que formarán nuestro corpus.

El primer criterio es de orden lingüístico, ya que todos los documentos que constituyen nuestro corpus están redactados en francés. De esta manera podemos establecer una correlación entre los textos apocalípticos en lengua latina, que son la fuente original, con los manuscritos de nuestro corpus para determinar qué temas y qué recursos pasaron de una literatura a otra y, por extensión, qué temas apocalípticos de la literatura latina se difundieron en lengua francesa.

El segundo criterio es de orden temporal, los documentos que hemos seleccionado son representativos de la temática apocalíptica en francés durante la Baja Edad Media. Los primeros documentos franceses de temática apocalíptica de los que tenemos noticia aparecen durante el siglo XIII. En el siglo XIV se reduce enormemente el número de textos de temática apocalíptica conservados en los fondos manuscritos; sin embargo, a lo largo del siglo XV, el número de manuscritos conservados aumenta ligeramente, acercándose a las cifras del siglo XIII. Los documentos que proponemos como corpus de temática apocalíptica medieval, pues, fueron redactados durante los últimos tres siglos de la Edad Media, del siglo XIII al XV.

El tercer y último criterio es la elección del fondo documental. La Bibliothèque nationale de France conserva el mayor número de manuscritos medievales de Francia, por lo que hemos optado por analizar su fondo manuscrito para seleccionar los documentos de temática apocalíptica que formarán nuestro corpus.

En este sentido, los manuscritos ${ }^{1}$ que analizaremos a continuación se circuns-

${ }^{1}$ A la hora de designar los manuscritos medievales, seguiremos las indicaciones del Comité des travaux
historiques et scientifiques de l'École Nationale de Chartes (2001), cuyo esquema es el siguiente: en 
criben a Francia, tanto a nivel geográfico como lingüístico. Además, prácticamente todos se conservan, como acabamos de señalar, en el fondo manuscrito de la BnF. En el caso del poema Les quinze signes du Jugement Dernier, que fue muy popular en la época, su difusión fue amplísima y encontramos manuscritos en Inglaterra, Bélgica, Holanda y Suiza (Mantou, 1966, 1967; von Kraemer, 1966; Rubio \& Trachsler, 2007).

\section{Temática apocalíptica en lengua romance}

Solo cinco temas de la tradición apocalíptica en lengua latina fueron adaptados a la incipiente literatura en lengua francesa. De estos cinco temas, tres tienen la más amplia difusión, esto es, el Anticristo, los signos del Juicio Final y el Juicio Final, y constituyen el grupo de temática principal de nuestro corpus. Los otros dos, el Último Emperador y los Pueblos Inmundos, forman el grupo de temática secundaria.

Dividir así los temas de la literatura apocalíptica responde a dos características inherentes a los documentos. La mayor parte de los manuscritos conservados con temática apocalíptica se incluye dentro primer grupo de literatura apocalíptica en lengua francesa, mientras que los temas del segundo grupo siempre forman parte, sea como escenas, sea como episodios, de otros textos más amplios.

En el grupo principal, el primer tema que encontramos es el tema del Anticristo, que, como su propio nombre indica, es el Enemigo Final de Cristo. Este fue uno de los temas de la literatura apocalíptica que más estimuló la imaginación de los autores patrísticos y medievales. Dicho personaje, como tema de la literatura apocalíptica, aparece en los textos del Nuevo Testamento y su influencia va aumentando con el tiempo sin sufrir grandes cambios.

El segundo tema de la temática apocalíptica principal son los signos del Juicio, que es una enumeración de cataclismos y fenómenos extraordinarios que anuncian el Juicio Final. Este el tema más difundido de la literatura apocalíptica medieval en lengua francesa por número de documentos conservados y difusión geográfica en Europa.

El tercer y último tema de este grupo principal es el Juicio Final, es decir, el momento último de la espera cristiana, el juicio en el que el Hijo de Dios separa a los justos de los pecadores, otorgando a cada uno castigo o recompensa según las obras realizadas durante su vida.

El tema del Anticristo tiene una relación directa con la literatura neotestamentaria, de donde surge, sin embargo, los signos del Juicio Final y el Juicio Final, son una preocupación más propia de la Antigüedad Tardía y la Alta Edad Media. Si el Anticristo se mantiene como tema literario desde su aparición en los Evangelios y otros textos de los primeros cristianos, los dos últimos surgen de dos temas de la literatura

primer lugar, se consigna la Biblioteca donde se conserva el manuscrito (en nuestro caso, BnF para la Bibliothèque nationale de France); seguidamente, el fondo donde se encuentra y el número asignado en el catálogo a dicho manuscrito; y para terminar, la foliación que indica dónde se halla el texto en cuestión dentro del volumen. 
patrística, la Duración del mundo y el Reino de los mil años. Desde el punto de vista temático, estos dos últimos temas dejan de ser relevantes en la literatura medieval en lengua francesa, en detrimento de los Signos del Juicio Final y del Juicio Final propiamente dicho.

Los dos temas que forman el grupo secundario de temática apocalíptica son el Último Emperador y los Pueblos Inmundos, que no tendrán ni la misma difusión ni recepción que los temas del grupo principal en lengua francesa.

El primero de estos temas secundarios, el último Emperador, es el personaje que representa al Imperio -el poder terrenal- y que someterá, en los últimos días del mundo, el poder imperial al Reino de Dios -el poder espiritual (Garstad, 2012)-.

El segundo de los temas es la leyenda de los pueblos inmundos, denominación genérica de aquellos que formarán las huestes del Anticristo durante los últimos momentos de la Cristiandad; esta denominación agrupa varias leyendas medievales (Garstad, 2012).

Una vez establecidos los temas principales y secundarios de la literatura apocalíptica en lengua romance, analizaremos los manuscritos que forman nuestro corpus.

\subsection{Temática principal}

En el corpus de documentos cuyo tema principal es el Anticristo, se observan dos subgrupos, diferenciados en función del tratamiento literario otorgado a dicho personaje.

El primer grupo incluye los manuscritos que narran la vida del Anticristo de manera biográfica, desde su nacimiento hasta su muerte. Estos manuscritos se incluyen en florilegios hagiográficos, de ahí que muchos estén titulados solo como d'Antéchrist, ya que imitan la estructura narrativa de las vidas de santos. A pesar de la unidad temática de los nueve manuscritos que forman este grupo, los títulos no están unificados: seis corresponden a esta denominación de (Vie) d'Antéchrist (BnF, f. fr. 411; BnF, f. fr. 412; BnF, f. fr. 987; BnF, f. fr. 24862; BnF, f. fr. 25532; BnF, n. a. fr. 10128), en tanto que los tres restantes tienen cada uno de ellos una denominación distinta: el primero de ellos responde a la denominación, más general, de Légende de l'Antécrist $(\mathrm{BnF}$, f. fr. 19531), el segundo al título de Comment Antecrist naistra (BnF, f. fr. 6647) y el tercero y último, a la denominación de Liber de Antecrist (ARS 3645).

El segundo grupo de manuscritos sobre el Anticristo se centra en las circunstancias que rodearán la llegada de este, sin interesarse por narrar su biografía. En este grupo encontramos ocho manuscritos, divididos a su vez en dos subgrupos en función del título: el primero de ellos se titula l'Avenement Antéchrist y cuenta con cinco manuscritos (BnF, f. fr. 413; BnF, f. fr. 1038; BnF, f. fr. 1157; BnF, f. fr. 1444; y BnF, f. fr. 23117); el segundo subgrupo se denomina La venue Antéchrist y está formado por tres manuscritos (BnF, f. fr. 422; BnF, f. fr. 909; y BnF, f. fr. 1370).

La gran mayoría de estos manuscritos son deudores del texto latino De ortu et tempore Antichristi de Adso de Montier-en-Der (Verhelst, 1976), redactado a mediados 
del siglo X por Adso, abad de Montier-en-Der por expreso deseo de Gerberga, esposa de Luis IV de Ultramar (Verhelst, 1976: 8). Este tratado recopila las especulaciones de la época acerca de la vida del Anticristo, de ahí el carácter biográfico con el que pasará a algunos de los textos en lengua francesa, como los manuscritos BnF, f. fr. 413, BnF, f. fr. $909, \mathrm{BnF}$, f. fr. 987 y BnF, f. fr. 1370, que son traducciones al francés de dicho texto latino.

En resumen, diecisiete manuscritos franceses tienen como tema central el Anticristo. La distribución temporal de estos, como hemos señalado más arriba, es desigual y se concentran en el siglo XIII, donde encontramos diez manuscritos. En el siglo XIV, y es una constante desde el punto de vista temático y documental, el número de manuscritos se reduce a su mínima expresión y solo encontramos un ejemplar. En el siglo $\mathrm{XV}$, sin embargo, el interés por el fin del mundo se reactiva y encontramos seis documentos que incluyen el tema del Anticristo.

En lo que respecta al aspecto formal, es significativo que, de los diecisiete manuscritos señalados, solo cuatro están redactados en verso (ms. f. fr. 411; ms. f. fr. 1444; ms. f. fr. 24862; ms. ARS 3645), mientras que los trece restantes están redactados en prosa. Es interesante señalar el aspecto formal porque el texto Des quinze Signes $d u$ Jugement Dernier, que veremos inmediatamente, fue mucho más difundido en verso que en prosa: de los treinta y dos manuscritos que se conservan, veintisiete están redactados en verso, mientras que solo cinco se redactaron en prosa.

Los manuscritos franceses que conservan el tema del Anticristo son los siguientes:

- BnF, f. fr. 411, fol. 287, en verso;

- BnF, f. fr. 412 fol. 226r-226v, en prosa;

- BnF, f. fr. 413, fol. 104-106, en prosa;

- BnF, f. fr. 422, fol. 127, en prosa;

- BnF, f. fr. 909, fol. 44v-45v, en prosa;

- BnF, f. fr. 987, fol. 247, en prosa;

- BnF, f. fr. 1038, fol. 162r-163v, en prosa;

- BnF, f. fr. 1157, fol. 239-243, en prosa;

- BnF, f. fr. 1370, fol. 135-136, en prosa;

- BnF, f. fr. 1444, fol. 60r-61, en verso;

- BnF, f. fr. 6647 ( Ci conte comment Antecrist naistra), fol. 234v-235r, en prosa;

- BnF, f. fr. 19531 (Légende de l'Antécrist), fol. 16v-19v, en prosa;

- BnF, f. fr. 23117, fol. 126v-135v, en prosa;

- BnF, f. fr. 24862, fol. 98v-101v, en verso;

- BnF, f. fr. 25532, fol. 318v-320, en prosa;

- BnF, n. a. fr. 10128, fol. 220, en prosa;

- ARS 3645 (Liber de Antecrist), fol. 4-24r, en verso. 
Los Signos del Juicio Final es el relato de las catástrofes y los prodigios que precederán el Juicio Final. Una de las grandes diferencias con el tema del Anticristo que acabamos de ver es su celeridad. Estos signos, quince en la versión extendida en Francia, se producirán en un intervalo de quince días, mientras que el relato del Anticristo, como biografía que es, se extiende durante varios años antes de llegar al Juicio Final.

Como ya hemos señalado, el tema de los Quince signos del Juicio Final fue el tema más difundido en Francia durante la Edad Media. Encontramos un gran número de manuscritos que conservan dicho tema, lo que, unido a la amplia difusión del francés como lengua durante el periodo tardomedieval en Europa, permite encontrar versiones más allá de las fronteras francesas.

Estos quince signos ocuparán un periodo de quince días, como decíamos, a signo por día, por lo que el tiempo que se les concede a los cristianos para prepararse ante el inminente Juicio es extremadamente reducido. Este periodo de contrición contrasta con el que se indica en los textos sobre del Anticristo, cuyo reinado durará tres ańos y medio, a los que se ańade cuarenta y cinco días una vez muerto, de modo que los cristianos tendrán tiempo de hacer penitencia y prepararse para el posterior Juicio Final, como aparece en la tradición apocalíptica previa. Esta diferencia invita a pensar que ambos temas evolucionaron de manera independiente el uno del otro.

El tema de los Quince signos fue ampliamente difundido bajo la forma de poema. La mayor parte de los poemas conservados de este tema, al contrario que el tema del Anticristo, están en octosílabos, seguida de una versión en alejandrinos. Que la versión más documentada sea en octosílabos, así como ciertas expresiones incluidas en el texto (como se observa en el primer verso del poema, "oez trestuit communément»), indican que se trata de la transcripción de una versión oral. Tenemos dos versiones, pues, en lengua francesa, una primera en verso octosilábico (Mantou, 1966), y otra, bastante más exigua, en prosa (Mantou, 1967).

A esto debemos añadir la diferencia en cuanto a la extensión del poema frente al texto en prosa. La extensión del poema octosilábico oscila entre los 167 versos en el texto publicado por Mantou (1966: 835-840) a los 444 versos del poema publicado por von Kraemer (1966: 61-92), mientras que el texto en prosa oscila entre las veintidós líneas del manuscrito 9106 de la Bibliothèque Royale de Belgique (Mantou, 1967: 840-841) y las veintiocho en el ms. fr. 1370. La versión en octosílabos con rima pareada, con una longitud media de 430 versos, es la forma más extendida de este tema: de los treinta y dos manuscritos que se conservan, veinticinco corresponden a dicho poema octosilábico. Los siete manuscritos restantes se dividen en dos textos en verso alejandrino (BnF, f. fr. 1444, 3516) y cinco en prosa (BnF, f. fr. 909, 1370, 15212, 19397; y Bruxelles, Bibliothèque Royale, 9106). 
Se conservan, pues, treinta y dos manuscritos de este tema apocalíptico en lengua francesa, de los que veinte se encuentran en el fondo manuscrito de la $\mathrm{BnF}$ (dieciocho en el fondo francés y dos en la Bibliothèque de l'Arsénal). Tres de estos manuscritos (ms. fr. 909, ms. fr. 1370 y ms. fr. 15212) son desconocidos para Reine Mantou y Erik von Kraemer y contienen la versión en prosa del tema de los Quince Signos: el manuscrito 1370 contiene dos versiones del tema, una en verso octosilábico y otra en prosa.

A los veinte manuscritos del fondo francés de la $\mathrm{BnF}$ hemos añadido los doce documentos conservados en otros fondos y estudiados por ambos autores: encontramos testimonios en otras dos ciudades francesas (Lyon y Tours) y, fuera de las fronteras de Francia, en Inglaterra (seis ejemplares), Bélgica (dos ejemplares), Suiza (un ejemplar) y Holanda (un ejemplar). Así, los manuscritos que contienen el tema de los Quince signos del Juicio Final ${ }^{2}$ en francés son los siguientes:

- ARS 2997, fol. 130rb³ [Mantou V / Kraemer Ø], en verso octosilábico;

- ARS 5204, fol. 97rc-98va [Mantou K / Kraemer L], en verso octosilábico;

- BnF, f. fr. 834, fol. 126ra-128rb [Mantou C / Kraemer A], en verso octosilábico;

- BnF, f. fr. 837, fol. 112rb-114rb [Mantou A / Kraemer B], en verso octosilábico;

- BnF, f. fr. 909, fol. 44r-45v, en prosa;

- BnF, f. fr. 1370, fol. 24vb-26rb [Mantou U/ Kraemer H], en verso octosilábico;

- BnF, f. fr. 1370, fol. 136r-139v [Mantou Ø/ Kraemer Ø], en prosa;

- BnF, f. fr. 1444, fol. 61 ra-va [Mantou], en verso alejandrino;

- BnF, f. fr. 3516, fol. 155r-156vc [Mantou], en verso alejandrino;

- BnF, f. fr. 1526, fol. 183ra-185vb [Mantou I / Kraemer C], en verso octosilábico;

- BnF, f. fr. 1533, fol. 33rb-36rb [Mantou A / Kraemer D], en verso octosilábico;

- BnF, f. fr. 2094, fol. 197vb-199rb [Mantou D /Kraemer E], en verso octosilábico;

- BnF, f. fr. 2168, fol. 186rb-188vb [Mantou T / Kraemer F], en verso octosilábico;

- Bnf, f. fr. 12483, fol. 151 ra-152 rb [Mantou P / Kraemer G], en verso octosilábico;

- BnF, f. fr. 14963, fol. xlvi va-xlviii r [Mantou H / Kraemer Ø], en verso octosilábico;

\footnotetext{
${ }^{2}$ Estos documentos fueron estudiados por Reine Mantou y Erik von Kraemer en 1966, de ahí que señalemos el lugar que ocupa dentro de su clasificación particular.

${ }^{3}$ Se trata de un manuscrito fragmentario.
} 
- BnF, f. fr. 15212, fol. 1r-1v, en prosa;

- BnF, f. fr. 19152, fol. 24vb-26rb [Mantou U/ Kraemer H], en verso octosilábico;

- BnF, f. fr. 19397, fol. 106v-108v [Mantou], en prosa;

- BnF, f. fr. 20040, fol. 118vb-120vb [Mantou O / Kraemer I], en verso octosilábico;

- Bnf, f. fr. 25545, fol. 104rb-106va [Mantou G / Kraemer K] ${ }^{4}$, en verso octosilábico;

- Bern, Burgerbibliothek, 354, fol. 60vb-63rb [Mantou R / Kraemer X], en verso octosilábico;

- Bruxelles, Bibliothèque Royale, 9106, fol. 253ra-253vb [Mantou], en prosa;

- Bruxelles, Bibliothèque Royale, 9229 / 9230 [Mantou M / Kraemer U], en verso octosilábico;

- Cambridge, Gonville and Caius College, 435 / 435, fol. 139rb-143ra [Mantou N / Kraemer Q], en verso octosilábico;

- Cambridge, St John's College, B 9, fol. 53rb-55rb [Mantou S / Kraemer S], en verso octosilábico;

- Cambridge, University Library, G.g. I. 1, fol. 113rb-36va [Mantou J / Kraemer Q], en verso octosilábico;

- La Haye, Bibliothèque Royale, 71. A. 24 (olim Y 389), fol. 72rc-73vb [Mantou $\mathrm{L}$

- / Kraemer V], en verso octosilábico;

- London, British Library, Add. 15606, fol. 124ra-127va [Mantou E / Kraemer O], en verso octosilábico;

- London, Lambeth Palace, 522, fol. 150r-158v [Mantou Q / Kraemer P], en verso octosilábico;

- Lyon, Bibliothèque Municipale, 584, fol. 14vb-16ra [Mantou X/ Kraemer M], en verso octosilábico;

- Oxford, Bodleian Library, C.C. College, 36, fol. 46ra-47ra [Mantou W / Kraemer $\mathrm{T}]^{5}$, en verso octosilábico;

- Tours, Bibliothèque Municipale, 927, fol. 40v-46v [Mantou F / Kraemer N], en verso octosilábico.

El último de los temas del grupo principal de la literatura apocalíptica es el Juicio Final, episodio en el que Jesús descenderá a la tierra para juzgar a la humanidad por sus obras y, en función de las mismas, recompensar a los justos o castigar a los pecadores. Tanto el tema del Anticristo como el tema de los Signos del Juicio Final tienen como episodio final el tema del Juicio en los textos franceses de la Baja Edad

${ }^{4}$ El poema se incluye en una antología de fabliaux.

${ }^{5}$ Incompleto por el final. 
Media. En el ms. fr. 2094, el tema del Juicio Final aparece tras el relato de los Quince signos, en tanto que en el ms. fr. 1370, aparece tras el tema del Anticristo.

Con esto queremos poner de relieve que, en el caso del tema que nos ocupa, se une a los otros dos temas que hemos visto con anterioridad, formando textos que relacionan los dos temas principales, a saber, el Anticristo y el Juicio Final y los Signos y el Juicio Final. Existen, además, cinco manuscritos, cuatro en prosa y uno en verso alejandrino, que tratan el tema del Juicio Final de forma aislada, sin relación con los otros dos temas mencionados. Del Juicio Final se conservan, pues, los siguientes documentos en la Biblioteca Nacional de Francia:

- Paris, BnF, f. fr. 1038, fol. 164r (siglo XIII, en prosa)

- Paris, BnF, f. fr. 1444, fol. 61rb (siglo XIII, en verso alejandrino)

- Paris, BnF, f. fr. 6447, fol. 235v (siglo XIII, en prosa)

- Paris, BnF, f. fr. 19531, fol. 19v (siglo XIII, en prosa)

- Paris, BnF, f. fr. 24868, fol. 235v (siglo XV, en prosa, en mal estado de conservación).

\subsection{Temática secundaria}

La característica principal de los textos pertenecientes a la temática secundaria es que no constituyen textos per se, sino que son solo escenas o episodios de un texto apocalíptico mayor, al contrario que los temas pertenecientes a temática principal, que sí forman textos independientes. Así, los dos temas que forman la temática secundaria, el Último Emperador y los Pueblos Inmundos, se encuentran, en la literatura en lengua francesa, dentro de otros textos, bien como anécdotas, bien como referencias.

En el caso del Último Emperador, que en origen representaba al Emperador de Bizancio, aparece por primera vez en el Apocalipsis de Pseudo-Metodio (siglo VII), aunque se encuentran referencias también en los oráculos sibilinos (Alexander, 1971). En dicho apocalipsis, Pseudo-Metodio usa la figura del emperador para atraer su atención sobre la invasión musulmana de la Siria cristiana de la que fue contemporáneo. Sin embargo, potenciado por la imprecisión del texto original, lo que en origen hacía referencia al Emperador de Bizancio, con la evolución y la difusión del texto, podía ser atribuido realmente a cualquier mandatario, como sucedió en múltiples ocasiones.

En este sentido, las alusiones al Último Emperador forman parte, en los documentos que se encuentran en Francia, de las traducciones que se hicieron del Tratado del Anticristo de Adso de Montier-en-Der, cuyo original es del siglo X, pero se tradujeron al francés entre los siglos XIII y XIV como hemos señalado más arriba. Así, esta mención al Último Emperador, dado el contexto del Tratado, hace referencia a la figura de Carlomagno como emperador de Francia y lo relaciona con los hechos narrados en la vida del Anticristo.

El tema de los Pueblos Inmundos surge de la eventualidad de una invasión por parte de otros pueblos, temor muy extendido en la Antigüedad y en la Edad Media. Al igual que el tema del Último Emperador, la invasión musulmana de Siria en el siglo 
VII alimenta los temores escatológicos de la población y estimulan la creatividad y la imaginación del autor del Apocalipsis al que acabamos de hacer referencia. Pseudo-Metodio asoció los ejércitos musulmanes que invadían Siria con las huestes del Anticristo de los últimos tiempos, que a su vez estaban asociados a los Pueblos Inmundos (Garstad, 2012: 7). Aunque esta es la primera mención al tema bajo esta denominación de Pueblos Inmundos, existen alusiones previas, especialmente en lo que respecta a la posibilidad de una invasión: en el libro de Ezequiel (Ez 38, 14-18) se señala a las huestes que invadirán Israel desde el norte.

Estos pueblos del Norte que invadirán Israel al final de los días que se menciona en el libro de Ezequiel evolucionarán con el tiempo hasta convertirse en los pueblos recluidos en el norte por parte de Alejandro Magno, episodio que aparece en la Vida y hazañas de Alejandro de Macedonia de Pseudo-Calístenes, en el siglo III. Todas estas leyendas y narraciones acabarán por confluir en el Apocalipsis de Pseudo-Metodio que, junto con la referencia del Pseudo-Calístenes, formarán el tema de los Pueblos Inmundos durante la Edad Media.

Así, la primera referencia a los Pueblos Inmundos en la literatura en lengua francesa se encuentra en las versiones del Roman d'Alexandre que se basan a su vez en una versión tardía de la Vida y hazañas de Alejandro de Macedonia que mezcla la leyenda de los Pueblos Inmundos encerrados en el Caspio con las referencias del Pseudo-Metodio que señalamos anteriormente ${ }^{6}$.

Es interesante señalar que el tema de los Pueblos Inmundos aparece también, en francés, en un contexto bastante alejado de la literatura apocalíptica, aunque más relacionado con la leyenda alejandrina: aparecen en el Livre dou devisement du Monde de Marco Polo (siglo XIII) y en el Livre des Merveilles du monde de Jean de Mandeville (s. XIV). Teniendo en cuenta que el tema central de ambos libros es el relato de los viajes de sus autores más allá de Europa, el tema de los Pueblos Inmundos adquiere un aspecto más geográfico que apocalíptico. De esta manera, tanto Marco Polo como Jean de Mandeville recuperan, quizás sin saberlo, el aspecto geográfico de la leyenda, que fue primordial durante la Antigüedad tardía (Anderson, 1928) y que desapareció en la Edad Media en detrimento del aspecto apocalíptico del tema.

\section{Conclusiones}

El texto más popular, en cuanto a número de copias conservadas, de la literatura apocalíptica fue, sin duda, el poema Des quinze signes du Jugement Dernier. Además, que se conserven copias en distintas bibliotecas más allá de las fronteras de Francia es también indicador de dicha popularidad. Le sigue, en número de manuscritos conservados, los textos relacionados con la figura del Anticristo y, finalmente, los textos cuyo tema es el Juicio Final.

\footnotetext{
${ }^{6}$ Esta versión tardía de la novela griega se encuentra en los manuscritos B y $\mathrm{M}$ de dicha obra, los únicos que conservan el episodio (III.29) relativo a los Pueblos Inmundos (Pseudo-Calístenes, 2002: 177-178).
} 
Estos tres temas, junto con el del Último Emperador y el de los Pueblos Inmundos, forman el corpus de temática apocalíptica en lengua romance durante el periodo medieval que proponemos. La literatura apocalíptica, cuyo origen se remonta al judaísmo anterior al exilio de Babilonia (587 a. C), ha evolucionado a largo de la historia occidental, hasta el periodo tardomedieval que nos ocupa, donde estos cinco temas, tres principales y dos secundarios, se difunden en lengua romance.

Los textos de contenido apocalíptico fueron copiados durante el siglo XII, aunque encontramos textos copiados en el siglo XIV, los menos numerosos, y en el siglo $\mathrm{XV}$. Los manuscritos incluidos en el corpus propuesto en este artículo demuestran que el interés en los textos apocalípticos fue fluctuando a lo largo de la Baja Edad Media, siendo el siglo XIV, como decíamos, el menos interesado en este tipo de textos.

Con este corpus queremos sentar las bases para el estudio de la temática apocalíptica en la Baja Edad Media francesa y situar este subgénero literario en relación no solo con la literatura en lengua francesa, sino con la historia de las mentalidades en dicho periodo. Aunque el número de manuscritos conservados sea reducido, sobre todo en comparación con otras obras medievales, los textos apocalípticos escritos durante la Edad Media en lengua francesa no dejaron de difundirse tanto en el tiempo como en el espacio. Aunque no el único, el poema Des quinze signes du Jugement Dernier es el mejor ejemplo, dada su difusión y su recepción en el periodo medieval, del interés que suscitaba tanto la temática como el pensamiento apocalípticos.

\section{REFERENCIAS BIBLIOGRÁFICAS}

AlberTZ, Rainer (1999): Historia de la religión de Israel en tiempos del Antiguo Testamento 1. De los comienzos hasta el final de la monarquía. Madrid, Trotta.

ALEXANDER, Paul Julius (1971): «Byzantium and the Migration of Literary Works and Motifs: the Legend of the Last Roman Emperor». Medievalia et Humanistica, 2, 47-68.

ANDERSON, Andrew Runni (1932): Alexander's gate; Gog and Magog and the inclosed Nations. Cambridge (Mass.), Mediaeval Academy of America.

COHN, Norman (1993): En pos del milenio. Revolucionarios milenaristas y anarquistas misticos de la Edad Media. Madrid, Alianza.

COLLINS, John Joseph (1998): The Apocalyptic Imagination: an Introduction to the Jewish Apocalyptic Literature. Grand Rapids / Cambridge, W. B. Eedermans.

COMITÉ DES TRAVAUX HISTORIQUES ET SCIENTIFIQUES (2001) : Conseils pour l'édition des textes médiévaux I-II. París, École Nationale de Chartes.

ELIADE, Mircea (2000): El mito del eterno retorno. Madrid, Alianza Editorial.

GARSTAD, Benjamin (2012): Apocalypse Pseudo-Methodius: an Alexandrian world chronicle. Cambridge, MA / Londres, Harvard University Press.

GNISCI, Armando (2002): Introducción a la literatura comparada. Madrid, Crítica. 
KRAEMER, Erik von (1966): Les Quinze signes du Jugement Dernier, poème anonyme de la fin $d u$ XII ou du début du XIII siècle publié d'après tous les manuscrits connus avec introduction, notes et glossaires. Helsinki, Societas scientiarum Fennica (Commentationes humanarum litterarum 38: 2).

MANDEVILLE, Jean (2000). Livre des merveilles du monde. Edición de Christiane Deluz. París, Éditions du CNRS.

MANTOU, Reine (1966): «Les quinze signes du Jugement Dernier, poème du XII ${ }^{e}$ siècle». Mémoires et publications de la Société des sciences des arts et des lettres du Hainaut, 80, 113121.

MANTOU, Reine (1967): «Le thème des "quinze signes du Jugement Dernier" dans la tradition française». Revue belge de Philologie et d'Histoire, 45: 3, 827-842.

MCGINN, Bernard (1994): Apocalypticism in the Western Tradition. Aldershot, Variorum.

MCGInN, Bernard (1998): Visions of the End. Apocalyptic traditions in the Middle Ages. Nueva York, Columbia University Press.

MARCO POLO, (2018): Le devisement du monde. Edición de Joël Blanchard y Michel Quereuil. Ginebra, Droz.

NAUPERT, Cristina (2001): La tematología comparatista. Entre teoría y práctica. Madrid, Arco Libros.

Pseudo-Calístenes (1977): Vida y hazañas de Alejandro de Macedonia. Edición de Carlos García Gual. Madrid, Gredos.

PUECH, Henri-Charles (1993): Historia de las religiones I-VI. Madrid, Siglo XXI.

RUBIO-REAL, Salvador \& Richard TRACHSLER (2007): «Le profil du recueil: observations sur le contexte manuscrit des Quinze Signes du Jugement dernien. Babel, 16, 101-122.

RUBIO-REAL, Salvador (2016): Temática apocalíptica en Francia y Castilla durante la Baja Edad Media. Tesis doctoral dirigida por Miguel Ángel Márquez Guerrero \& Pablo Zambrano Carballo. Universidad de Huelva. URL: http://hdl.handle.net/10272/12955.

Verhelst, Daniel (1976): Adso de Montier-en-Der, De Ortu et tempore Antichristi. Turnhout, Brepols (Corpus Christianorum. Continuatio Mediaevalis, 45). 